\title{
IN MEMORY OF PAVEL PETROVICH POLUEKTOV
}

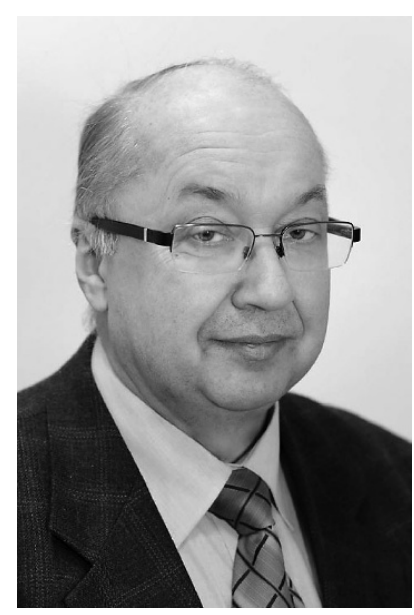

Pavel Petrovich Poluektov, Doctor of Physical-Mathematical Sciences, Professor, active member of the Russian Academy of Natural Sciences, Laureate of the USSR Council of Ministers Prize, participant in the cleanup operations after the accident at the Chernobyl NPP, Chief Scientist at the Bochvar All-Russia Research Institute for Inorganic Materials (VNIINM), and member of the editorial staff of our journal, passed away on March 10, 2015 after a serious illness.

P. Poluektov was born on August 22, 1949 in Moscow. In 1974, he graduated with honors from the Moscow Engineering Physics Institute and in 1977 he received a candidate's degree in physical-mathematical sciences. In 1977, he began work at the VNIINM, where served in positions ranging from junior researcher to deputy director general and chief scientist (since 1974).

P. Poluektov was a prominent scientist in the field of radwaste management and reprocessing of spent nuclear fuel, including modeling technological processes. In 1994, he defended his doctoral dissertation and in 2002 he was named professor. Under his scientific management, tens of scientific R\&D projects were completed, several doctoral and candidate's dissertations were defended, and nearly 200 works were published in domestic and foreign publications.

P. Poluektov was active in international work. For many years, he served as a representative of Rosatom on high-profile committees of the IAEA and a participant in IAEA projects.

P. Poluektov was a multifaceted person. He possessed encyclopedic knowledge in science, engineering, and culture; he loved books, especially poetry, which he also wrote. He was benevolent, ready to assist in any situation; he had many devoted friends; he was a loving husband and caring father and grandfather.

P. Poluektov will forever remain a blessed memory to all who knew him.

Translated from Atomnaya Énergiya, Vol. 118, No. 3, p. 179, March, 2015. 